\title{
Analysis of Thermal Bridges in Loggias of Pre-Cast Concrete Apartment Buildings
}

\author{
Lubor Kalousek ${ }^{1, *}$, Roman Brzoñ ${ }^{1}$, and Zuzana Fišarová ${ }^{1}$ \\ ${ }^{1}$ Brno University of Technology, Faculty of Civil Engineering, Institute of Building Structures, \\ Veveří 331/95, 60200 Brno, Czech Republic
}

\begin{abstract}
The issue of complex regeneration of old pre-cast concrete apartment buildings is still a current task of everyday construction practice in the Czech Republic. When designing a new thermal insulation for the envelope of these buildings, we often encounter with critical assembly details. The correct solution of these details requires a detailed assessment in terms of the requirements of thermal protection of buildings. A correct assessment of these critical details is often very challenging and the ordinary designer is virtually unable to do it himself. This paper presents a practical and theoretical example of the design, solution and assessment of additional insulation of loggia loadbearing structures. Using the Ansys software platform, the critical details in $3 \mathrm{D}$ were designed and the influence of new thermal insulation on removal of the building defects was assessed. In conclusion, several proposals for possible rehabilitations and their expected efficiency were summarized.
\end{abstract}

\section{Problem statement}

The issue of complex regeneration of pre-cast concrete buildings is still a current task of everyday construction practice in the Czech Republic. When designing a new thermal insulation for the envelope of these buildings, we often encounter with critical assembly details whose detailed rehabilitation is typically underestimated in common construction practice, which might lead to the occurrence of defects or failures. This paper presents a real case study how to insulate the connection between the loadbearing loggia side wall and the external wall of pre-cast concrete building of T $06 \mathrm{~B}-\mathrm{KD}$ system, see Fig. 1.

The T 06 B pre-cast concrete building system was designed as short span building system with loadbearing transversal walls and stiffening longitudinal walls when the unified span of the transversal was $3.6 \mathrm{~m}$, and the constructional height of the building was $2.8 \mathrm{~m}$. They were built as terraced or detached buildings, up to 8 floors high.

T $06 \mathrm{~B}-\mathrm{KD}$ system is apparently the most widespread type of pre-cast concrete buildings in the Czech Republic which started to be used during 1960 - 1965 and its construction continued throughout 1980s, when the building envelope was modified according to the requirements of revised Czech Technical Standard ČSN 730540 from the year 1977 [1]. Especially building envelopes of T 06 B building system display large

\footnotetext{
* Corresponding author: kalousek.1@,fce.vutbr.cz
} 
number of variants which cannot be simply generalized. For example, the assessed South Moravian regional material variant was executed with slag and expanded clay concrete envelope or as a plain expanded clay variant. According to the requirements of the revised ČSN 73 0540:1977 standard, a sandwich variant was used which was complemented by thermal insulation from foam polystyrene of $60 \mathrm{~mm}$ width in the sandwich panel [2].

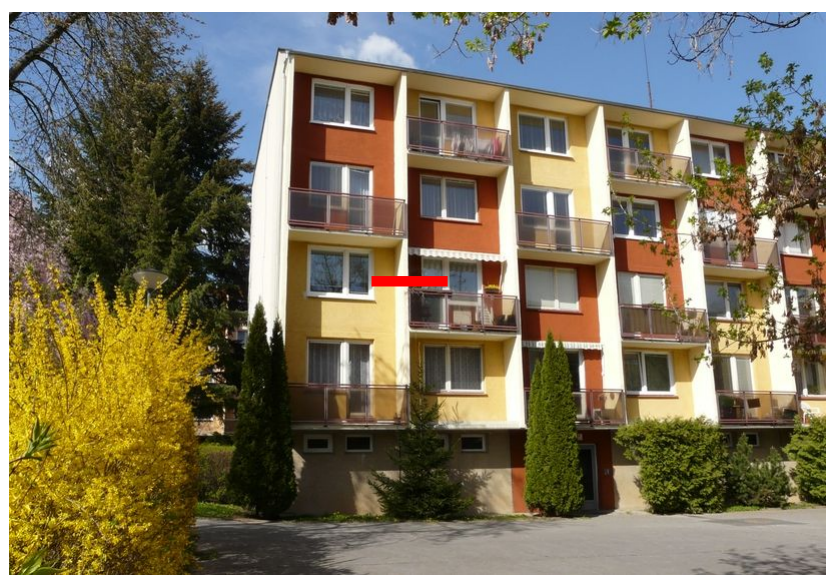

Fig. 1. Case study pre-cast concrete building $-\mathrm{T} 06 \mathrm{~B}-\mathrm{KD}$ building system, view of markedly broken façade with protruding walls and balconies. Red mark points to the place of the cross section in the assessed critical detail.

Further analysis was performed on older variant of T 06 B - KD from the year 1975 which has external elements from slag and expanded clay concrete which are single layer, $300 \mathrm{~mm}$ wide, finished by a thin layer of plaster inside and exposed washed out concrete outside. The side loggia walls are $140 \mathrm{~mm}$ wide. Common failure was leaking into the structure of the elements and into the interior of the buildings. Some buildings sporadically showed problems when ETICS was applied due to the low material strength [2].

\section{Purpose of study}

The ways of insulation of building envelopes in the Czech Republic and the defects caused by thermal bridges have been dealt in detail e.g. in [3]. In the past this problem in older buildings was hardly ever solved, because in the context of the whole building envelope and the high values of heat transfer coefficient, these places did not represent a substantial problem, which is visible in the results presented in Table 1, when the linear heat transfer coefficient in the uninsulated variant composes only about $1.3 \%$ of all heat transfer in the assessed detail.

Although the application of ETICS is currently generally well-known and long-time verified in the practice, it is common practice that buildings are insulated only partially and thus give rise to inadequate solutions of critical details. The reasons for such partial solutions are most frequently economical, spatial and aesthetic requirements. The question is what the real influence of such a partial insulation is in comparison with a complex solution as will be shown on the case study.

The current trend focussing on the airtightness of the building envelope using very tight opening elements (windows, doors etc.) causes the rise of interior relative air humidity. Due to this rise we must consider the stricter requirements on interior surface temperature, specifically the temperature factor. It is frequently forgotten to assess and eliminate thermal bridges in the form of local and linear heat transfer coefficient. These assessments lead to 
indication of critical areas more often than simple determination of the surface temperature. Their localization and optimization may lead to the reduction or elimination of large heat losses which have significant impact on the energy balance.

\section{Methods}

Most of the available programmes used in the design practice operate with 2D model. Although it is a spatial problem, the transformation into 2D plane is mostly sufficient. In this case it is necessary to take into consideration that the limit values might be worse in the corners and other complicated areas. To prevent the complications, we may use the programmes which are able to work in $3 \mathrm{D}$ and to model the most complex, and frequently, the most critical areas. For the solution of the 3D model study in this paper was used the Ansys programme, see Fig. 2. It was used to assess the 3D detail of the connection between the vertical protruding constructions in the structure of the balcony and the gable wall. Other variants presented in Table 1 were assessed in the 2D Area programme.

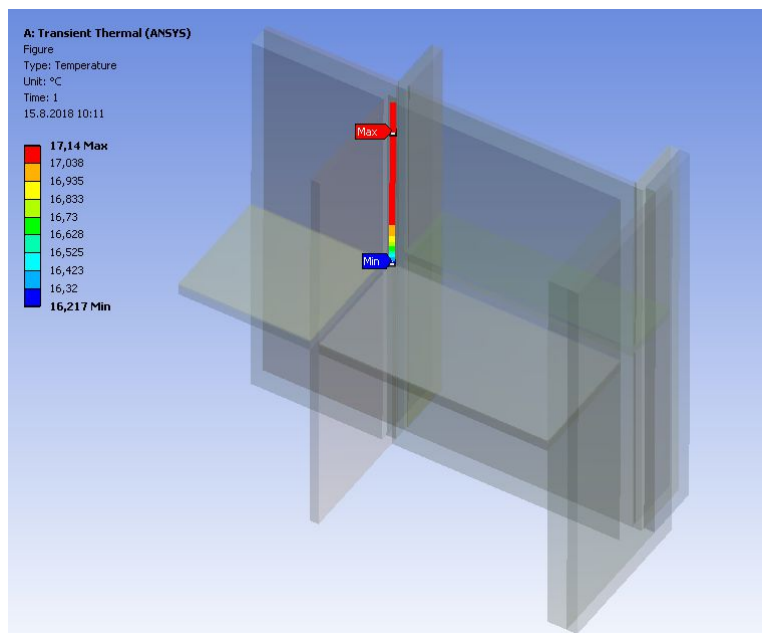

Fig. 2. Ansys programme output simulating three dimensions - the detail of the assessed construction, $3 \mathrm{D}$ view of the corner flat floor plan and the connection to the loggia with the side walls.

\section{Findings and results}

Due to the extent of this case study only one representative critical detail was selected and analysed in detail, namely the connection of the loggia side wall to the peripheral wall (Fig. 1 and 2).

For a comparison, in total 16 variants were selected which are divided into four groups and the details are described in Table 1. The first group represent the existing non-insulated variant. The other groups differ in the width of the wall insulation $(80,120$ and $160 \mathrm{~mm}$ of EPS GreyWall thermal insulation) and further in the width of the insulation on the loggia protruding wall $(0,20,40$ and $60 \mathrm{~mm}$ of EPS $70 \mathrm{~F}$ thermal insulation).

The first graph (Fig. 3) shows the impact of the whole heat flux (for the modelled area) on the construction and the implication for the surface temperature and the linear heat transfer coefficient. The large differences between insulated and non-insulated protruding wall variant are clearly visible. The reduction of the heat flux and internal surface temperature in each of the proposed modification is considerable. 


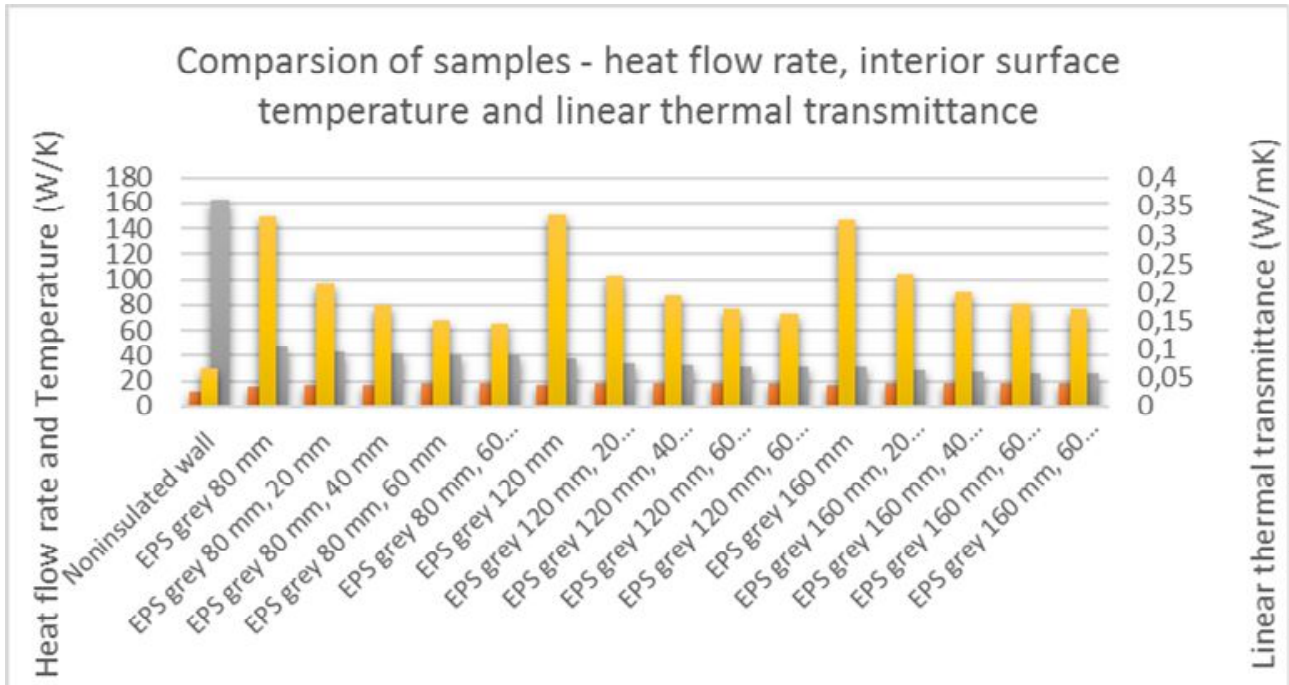

घ Interior surface temperature $\mathbf{n}$ Heat flow rate $\mathbf{w}$ Linear thermal transmittance

Fig. 3. Comparison of individual variants and their dependency on the total heat flux.

When compared the impact of individual insulation variants concerning two assessed factors: interior surface temperature and temperature factor in Fig. 3. It is obvious that the influence of the insulation of the protruding wall does not have, in terms of the interior surface temperature, such a big impact as on the value of the linear coefficient.

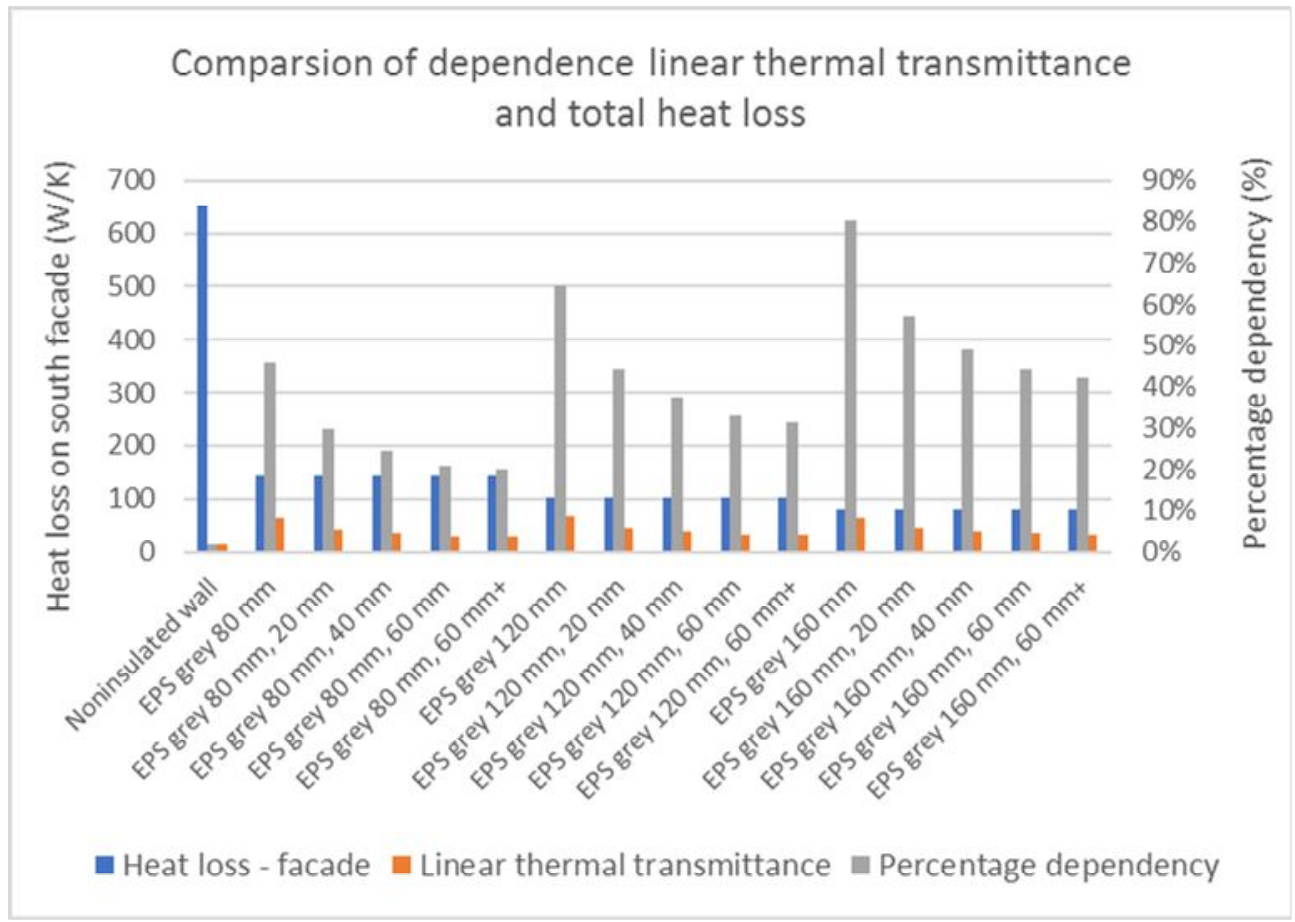

Fig. 4. Transfer of the linear coefficient values impact on the total losses of façade transfer. 
In order to express how big influence the linear heat transfer coefficient has in the whole context, we performed the assessment of the total loss of the transfer of one façade, which depicts the graph Fig. 4. As simplification, the opening infills are not considered, thus it is theoretically net heat flux through the building envelope. We also ignored the influence of the thermal bridge of the balcony, so that we can calculate the assessed area. Therefore, it is probable that the total impact of thermal bridges in the whole façade surface will be higher, even though our calculations do not consider the opening infills. It has turned out that in case of the thermal insulation with the values recommended in [1] but omitting the reduction of this thermal bridge, the impact on the overall heat flux is $65 \%$. In case of application of $20 \mathrm{~mm}$ EPS 70F thermal insulation, the influence reduces to $45 \%$, but the surface temperature will rise only from $16,73^{\circ} \mathrm{C}$ to $17,57^{\circ} \mathrm{C}$. In case of the variants when the peripheral construction is insulated according to the values required for the passive house standard, this influence is up to $80 \%$, therefore considerable.

A table showing all values for the assessed variants is shown below. There is also determined the dependence of linear coefficient on the total heat flux through the area of the wall in the assessed area of $3.6 \mathrm{~m}$ width. Also from these values it is evident, how important it is to reduce these areas in the course of the pre-cast concrete buildings revitalization. The grey colour in the table denotes the values which do not meet the standard [1]. In terms of the linear heat transfer coefficient, the requirement is $0.2 \mathrm{~W} /(\mathrm{m} . \mathrm{K})$, which in our case means the application of at least $40 \mathrm{~mm}$ of insulation with the thermal conductivity $0.032 \mathrm{~W} /(\mathrm{m} . \mathrm{K})$, to meet the requirement.

\section{Conclusions and recommendation}

This presented model situation brings several interesting findings. The approach to the similar buildings must be complex and considered from several angles. A solution when we only pursue to insulate the building regardless the material, its width or its area is wrong and often leads to subsequent defects and failures.

The designer must assess the building in all respects and focus predominantly on the critical areas of the project, i.e. the details. It is suitable to perform energy evaluation which will show the economically and functionally suitable variant and will help the investor to decide.

As the case study has shown, it is always necessary to insulate also the constructions which are protruding outside the main building envelope or extend into the unheated spaces. The resulting energy reduction for building heating will safely compensate the higher cost in the defined period. It is also visible that in case of the $2 \mathrm{D}$ and $3 \mathrm{D}$ comparison, the difference in the surface temperature might be even higher, in our model the temperature drop is about $1^{\circ} \mathrm{C}$ more.

To determine and assess the critical areas is not complicated, even though in practice it is often omitted. Our 2D simulations, and in one case 3D simulation, clearly show that in common practice the 2D solution is sufficient for most cases. Every attempt to solve and revitalize the critical areas with sufficient insulation will result in higher temperature comfort and reduction of unfavourable impacts on the interior climate environment as well as on the building construction.

The assessment has shown that to meet the requirements for the critical thermal factor, only insulation of envelope wall, between loggia side walls, is sufficient. From the complex point of view, namely when evaluating the heat flux, it has been however shown that the omission of protruding constructions of loggia walls from the insulation will lead to a significant rise in heat losses. Thus, only insulation of envelope wall, without insulation of loggia side walls, seemed to be a considerably inefficient and not meeting the requirements of the valid standards [1]. 
Table 1. Results of calculating samples.

\begin{tabular}{|c|c|c|c|c|}
\hline Assessed variants & $\begin{array}{c}\begin{array}{c}\text { U-value } \\
\text { insulated } \\
\text { wall }\end{array} \\
W /\left(m^{2} . K\right)\end{array}$ & $\begin{array}{c}\begin{array}{c}\text { Interior } \\
\text { surface } \\
\text { temperature } \\
\text { in corner }\end{array} \\
{ }^{\circ} \mathrm{C} \\
\end{array}$ & $\begin{array}{c}\begin{array}{c}\text { Linear } \\
\text { coefficient } \\
\text { value }\end{array} \\
W /(m . K) \\
\end{array}$ & $\begin{array}{c}\text { Comparsion } \\
\text { od thermal } \\
\text { bridge to } \\
\text { heat flow } \\
\text { throw wall } \\
\% \\
\end{array}$ \\
\hline Non-insulated building (original state) & 1.42 & 11.91 & 0.07 & $1.3 \%$ \\
\hline EPS grey $80 \mathrm{~mm}, \mathrm{LW}$ Non-insulated & 0.31 & 16.16 & 0.33 & $29.5 \%$ \\
\hline EPS grey $80 \mathrm{~mm}$, LW EPS 70F $20 \mathrm{~mm}$ & 0.31 & 17.10 & 0.22 & $19.2 \%$ \\
\hline EPS grey $80 \mathrm{~mm}, \mathrm{LW}$ EPS $70 \mathrm{~F} 40 \mathrm{~mm}$ & 0.31 & 17.41 & 0.18 & $15.7 \%$ \\
\hline EPS grey $80 \mathrm{~mm}$, LW EPS 70F $60 \mathrm{~mm}$ & 0.31 & 17.61 & 0.15 & $13.5 \%$ \\
\hline EPS grey $80 \mathrm{~mm}, \mathrm{LW}$ EPS 70F $60 \mathrm{~mm}+\mathrm{FS}$ & 0.31 & 17.67 & 0.14 & $12.9 \%$ \\
\hline EPS grey $120 \mathrm{~mm}$, LW Non-insulated & 0.22 & 16.73 & 0.33 & $41.4 \%$ \\
\hline EPS grey $120 \mathrm{~mm}$, LW EPS 70F $20 \mathrm{~mm}$ & 0.22 & 17.57 & 0.23 & $28.4 \%$ \\
\hline EPS grey $120 \mathrm{~mm}$, LW EPS 70F $40 \mathrm{~mm}$ & 0.22 & 17.85 & 0.19 & $24.0 \%$ \\
\hline EPS grey $120 \mathrm{~mm}$, LW EPS 70F $60 \mathrm{~mm}$ & 0.22 & 18.03 & 0.17 & $21.2 \%$ \\
\hline EPS grey $120 \mathrm{~mm}$, LW EPS 70F $60 \mathrm{~mm}+\mathrm{FS}$ & 0.22 & 18.10 & 0.16 & $20.2 \%$ \\
\hline EPS grey $160 \mathrm{~mm}$, LW Non-insulated & 0.18 & 17.13 & 0.33 & $51.6 \%$ \\
\hline EPS grey $160 \mathrm{~mm}$, LW EPS 70F $20 \mathrm{~mm}$ & 0.18 & 17.88 & 0.23 & $36.8 \%$ \\
\hline EPS grey $160 \mathrm{~mm}$, LW EPS 70F $40 \mathrm{~mm}$ & 0.18 & 18.14 & 0.20 & $31.6 \%$ \\
\hline EPS grey $160 \mathrm{~mm}$, LW EPS 70F $60 \mathrm{~mm}$ & 0.18 & 18.30 & 0.18 & $28.5 \%$ \\
\hline EPS grey $160 \mathrm{~mm}$, LW EPS 70F $60 \mathrm{~mm}+\mathrm{FS}$ & 0.18 & 18.37 & 0.17 & $27.1 \%$ \\
\hline
\end{tabular}

This paper has been worked out under the project No. LO1408 "AdMaS UP - Advanced Materials, Structures and Technologies", supported by Ministry of Education, Youth and Sports under the „National Sustainability Programme I".

\section{References}

1. ČSN 73 0540-1, 2, 3, 4 Czech Technical Standard: Thermal protection of buildings (Czech Office for Standards, Metrology and Testing, Prague, 2005, 2007, 2011)

2. J. Šafránek, P. Kučera, I/11 Complex reconstruction of panel houses of building systems $T 06$ B from the point of view of thermal protection, building acoustics, fire safety and technical equipment of buildings (I /11 Komplexni regenerace panelových domů stavebni soustavy T 06 B z hlediska tepelné techniky, stavebni akustiky, požární bezpečnosti a TZB) (IC ČKAIT, Prague, 2000)

3. V. Petránek, R. Šubrt, J. Plachý, L. Nevřivová, T. Petř́iček, L. Kalousek, Z. Caha, AMR 732-733, 182-185 (2013) 